\section{Gustatory cross adaptation: Sourness and bitterness*}

\section{DONALD H. McBURNEY $†$, DAVID V. SMITH $\dagger \dagger$ and THOMAS R. SHICK University of Pittsburgh, Pittsburgh, Pennsylvania 15213}

In five experiments, Ss were presented with a variety of sour and bitter compounds after the tongue was rinsed with distilled $\mathrm{H}_{2} \mathrm{O}, \mathrm{QHCl}$, urea, or citric acid. All the acids tested were significantly less sour following adaptation to citric acid than after adaptation to distilled $H, O$. The taste of these acids was not affected by rinsing the tongue with $\mathrm{QHCl}$ or urea. QHCl adaptation markedly reduced the bitterness of some compounds, while having little effect on others, including urea and citric acid. Both urea and citric acid had smaller but reliable effects on the bitterness of QHCl. These apparently incompatible results do not seem to be the result of a simple verbal confusion between sourness and bitterness. Some compounds were not affected by any of the adapting conditions. The coding mechanisms for the sourness of acids appears to be relatively simple, while that for bitterness is more complex.

It is generally accepted that if adaptation to one stimulus reduces the response to another stimulus the receptor mechanism responsible for coding the two stimuli is common to them. Smith and McBurney (1969) found with the sense of taste that adaptation of $\mathrm{NaCl}$ reduced the saltiness of the 11 salts tested, indicating that there may be one mechanism for saltiness. McBurney (1972) showed that sucrose adaptation reduced the sweetness of all sweet substances tested. Hahn (1949) found that cross adaptation occurred between acids, but with the bitter quality adaptation was found between some but not all stimuli. Hahn's results suggest that the mechanisms underlying the sour taste may be relatively simple, while the mechanisms encoding bitterness may be more complex.

The present study, in which a series of five experiments is reported, was originally designed to examine the effects of adaptation to quinine hydrochloride (QHCl) on the bitter taste of several other bitter compounds. The study was later expanded to include adaptation to urea and citric acid as well as to examine the relationships between sourness and bitterness as affected by adaptation to these three compounds.

* This research was supported in part by United States Public Health Research Grant 5RO1 NS0783-04, and United States Public Health Service Predoctoral Fellowship 5-FO 1-GM-35,975-02. A portion of these resuits was reported at the Third International Symposium on Olfaction and Taste held at the Rockefeller University in 1968.

+Requests for reprints should be sent to Donald H. McBurney, Department of Psychology, University of Pittsburih, Pittsburgh, Pa. 15213.

+ Now at the University of Wyoming, Laramie.

\section{GENERAL METHOD} Apparatus

All solutions were made with distilled water and maintained at $34^{\circ} \mathrm{C}$ in a water bath (see McBurney, 1966). All test stimuli were equated in total subjective intensity to that of $0.1 \mathrm{M}$ $\mathrm{NaCl}$ by nonmodulus magnitude estimation prior to the experiment. The concentrations of some test stimuli were adjusted from one experiment to another when it was apparent that they were too weak or too strong compared to the other test stimuli. The adapting stimuli were of the same total subjective intensity as the test stimuli.

\section{Procedure}

Ss sat with the tongue extended between the lips so that a gravity flow system delivered the solutions to the dorsal tongue surface, eliminating the influence of saliva. The solutions flowed over the tongue and into a collecting funnel beneath the chin. The Ss were instructed to give magnitude estimates of the intensity of each of the test stimuli. No modulus was employed. They were further asked to divide this estimate among the appropriate taste qualities for each stimulus. The $\mathrm{Ss}$ recorded their responses on a data sheet containing columns for the qualities of salty, sour, sweet, and bitter, as well as total intensity. Prior to the experiment, the Ss were given practice estimating the lengths of lines and the lengths of the parts of the lines that were various colors. For example, a practice line might have been 6 in. long, 3 in. of which were red and 3 in. of which were black. The $S$ would then equally divide his estimate of the total line length in order to obtain an estimate of the length of each component color. In the same fashion the Ss were to judge the intensity of the test stimuli and then divide that estimate appropriately among the taste qualities.

In the first four experiments, the Ss were presented each of the test stimuli once after adaptation to distilled $\mathrm{H}_{2} \mathrm{O}$ and once after adaptation to the adapting stimulus during a 1 -h session on each of 4 days. The adapting stimulus or the distilled $\mathrm{H}_{2} \mathrm{O}$ rinse flowed for $3 \mathrm{~min}$ before the first stimulus of each condition, and for 30 sec between the succeeding stimuli. The test stimuli were presented in random order, and the order of the adapting conditions was alternated. In the final experiment, the Ss were presented each of the test stimuli twice under each condition, once on each of 2 test days. The durations of the adapting stimuli were the same as in the preceding experiments. The orders of the test stimuli and the adapting conditions were random. Prior to each session in all experiments, the Ss were presented with $0.1 \mathrm{M} \mathrm{NaCl}, 0.001 \mathrm{M}$ tartaric acid, $0.18 \mathrm{M}$ sucrose, and $0.001 \mathrm{M}$ quinine hydrochloride (QHCl) as examples of the four "basic" taste qualities. The responses of each $S$ were multipled by a constant so that each S's arithmetic mean magnitude estimate of total intensity of all of the stimuli after $\mathrm{H}_{2} \mathrm{O}$ adaptation was the same. The arithmetic mean was chosen because of the large number of zeros.

\section{EXPERIMENT 1:}

\section{QUININE HYDROCHLORIDE ADAPTATION Method}

Subjects. Fifteen Ss were used, eight males and seven females. None smoked and all but one were naive about the purpose of the study.

Solutions. The six test stimuli were the following: $0.0001 \mathrm{M} \mathrm{QHCl}$, $0.0001 \mathrm{M} \quad \mathrm{QSO}_{1}, 0.25 \mathrm{M} \mathrm{MgSO}_{4}$, $1.0 \mathrm{M}$ urea, $0.003 \mathrm{M}$ PTC, and distilled $\mathrm{H}_{2} \mathrm{O}$. The adapting stimuli were distilled $\mathrm{H}_{2} \mathrm{O}$ and $0.0001 \mathrm{MQHCl}$.

\section{Results}

The effects of QHCl adaptation on the sourness and bitterness of the test stimuli are shown in Fig. 1. The circles represent the taste of the stimuli following a distilled $\mathrm{H}_{2} \mathrm{O}$ rinse and the triangles depict the taste after $\mathrm{QHCl}$ adaptation. The line indicates the amount of change between the two conditions. The asterisks indicate that the change in bitterness was statistically significant at the .05 level (two-tailed), while the os indicate a significant change in sourness. It is evident that the bitter taste of urea and $\mathrm{MgSO}$, was not affected by QHCl. The taste of PTC also showed no significant change. Both QHCl and $\mathrm{QSO}_{4}$ were also reported as partially 


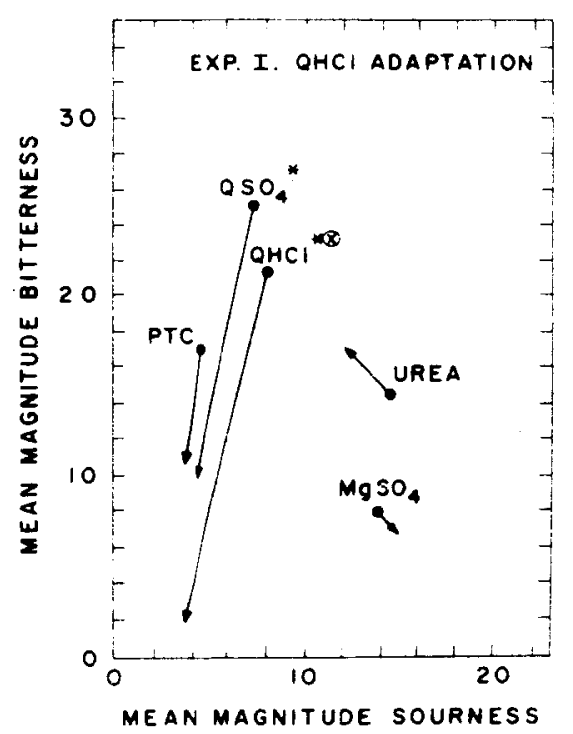

Fig. 1. Mean magnitude estimates of the sourness and bitterness of five stimuli after adaptation to distilled $\mathrm{H}_{2} \mathrm{O}$ and to $0.0001 \mathrm{M} \mathrm{QHCl}$.

sour, and the sourness of $\mathrm{QHCl}$ was significantly reduced after adaptation to $\mathrm{QHCl}$. Distilled $\mathrm{H}_{2} \mathrm{O}$ is not shown because it was not significantly sour or bitter following either a distilled $\mathrm{H}_{2} \mathrm{O}$ rinse or a $\mathrm{QHCl}$ rinse. The mean magnitude estimates of bitterness are seen to decrease for $\mathrm{QHCl}$ and $\mathrm{QSO}_{4}$ following $\mathrm{QHCl}$ adaptation.

EXPERIMENT 2:

\section{QUININE HYDROCHLORIDE} ADAPTATION

Because of the limited sample of compounds used in Experiment 1 it was not clear whether QHCl would adapt only the bitterness of quinine salts or if it would also have an effect on other compounds.

\section{Method}

Subjects. Fifteen Ss were used, 10 males and 5 females. None smoked and all but one were naive about the purpose of the study.

Solutions. The 12 test stimuli were the following: $0.0001 \mathrm{M}$ QHC1, $0.00001 \mathrm{M} \quad \mathrm{QSO}_{4}, 0.25 \mathrm{M} \mathrm{MgSO}_{4}$, $0.82 \mathrm{M}$ urea, $0.0003 \mathrm{M}$ PTC, $0.0002 \mathrm{M}$ tannic acid, $0.1 \mathrm{M}$ caffeine, $0.001 \mathrm{M}$ sucrose octa-acetate (SOA), $0.003 \mathrm{M}$ Na-saccharin, $0.026 \mathrm{M} \mathrm{CaCl}_{2}, 0.32 \mathrm{M}$ $\mathrm{KNO}_{3}, 0.11 \mathrm{M} \mathrm{KCl}$. The adapting stimuli were distilled $\mathrm{H}_{2} \mathrm{O}$ and $0.0001 \mathrm{M}$ QHCl.

\section{Results}

Figure 2 shows that the results of Experiment 2 were similar to those of Experiment 1. QHCl and $\mathrm{QSO}_{4}$ were both practically tasteless following $\mathrm{QHCl}$ adaptation (the concentration of $\mathrm{QSO}_{4}$ used in the second experiment was one log step weaker than that used in Experiment 1). Again, the bitter taste of urea, MgSO and PTC was not affected by $\mathrm{QHCl}$ adaptation. Equally evident, however, is the significant reduction in the bitterness of both caffeine and sucrose octa-acetate. The bitter taste of $\mathrm{KNO}_{3}$ and tannic acid, like that of urea, $\mathrm{MgSO}_{4}$ and PTC was not reduced by $\mathrm{QHCl}$ adaptation. Three of the test stimuli, Na-saccharin, $\mathrm{CaCl}_{2}, . \mathrm{KCl}$, were not reported as appreciably bitter in this experiment. However, $\mathrm{CaCl}_{2}$ was reported to be sour and this sourness was reduced by $\mathrm{QHCl}$ adaptation. In a previous experiment (Smith \& McBurney, 1969), $\mathrm{KCl}$ and $\mathrm{CaCl}_{2}$ were reported as more bitter than sour. Perhaps these salts appeared to taste less bitter in contrast to the other bitter stimuli in the present experiment than when judged among a group of salty stimuli. The sweetness of the test compounds is not shown, but a significant increase in sweetness was found following $\mathrm{QHCl}$ in six of the stimuli (QHCl, $\mathrm{QSO}_{4}, \mathrm{PTC}$, caffeine, $\mathrm{SOA}$, and $\mathrm{CaCl}_{2}$ ). It has been previously demonstrated that $\mathrm{QHCl}$ adaptation produces a sweet taste in distilled $\mathrm{H}_{2} \mathrm{O}$ (McBurney, 1969).

\section{EXPERIMENT 3: UREA ADAPTATION}

The fact that $\mathrm{QHCl}$ adaptation does not reduce the bitterness of all the stimuli implies that there is not a single mechanism responsible for coding the bitter taste. The next experiment involved adaptation to a stimulus that was not affected by $\mathrm{QHCl}$ adaptation.

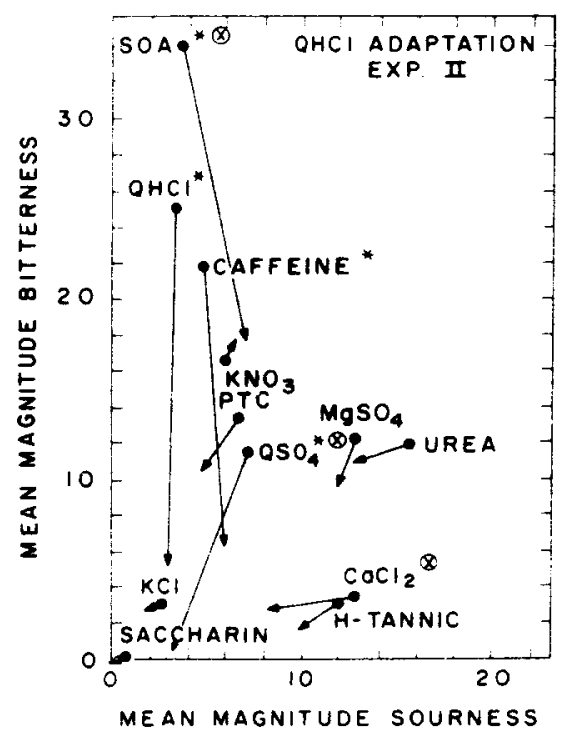

Fig. 2. Mean magnitude estimates of the sourness and bitterness of 12 stimuli after adaptation to distilled $\mathrm{H}_{2} \mathrm{O}$ and to $0.0001 \mathrm{M} \mathrm{QHCl}$.

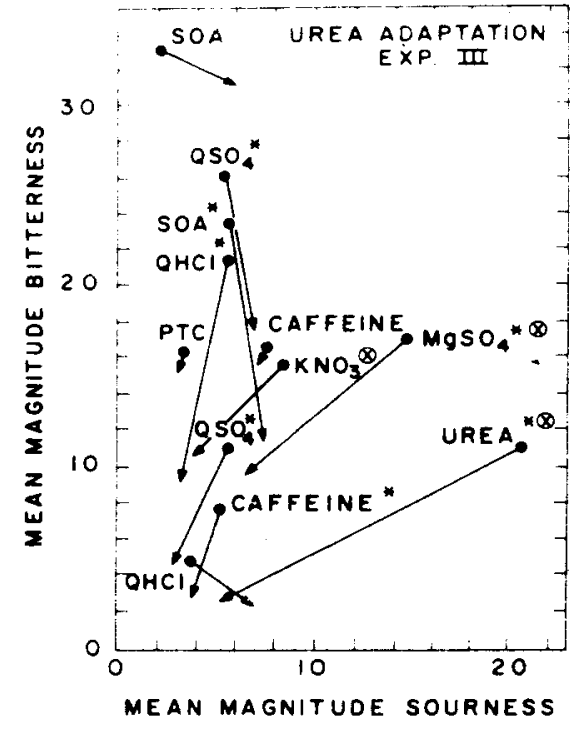

Fig. 3. Mean magnitude estimates of the sourness and bitterness of 12 stimuli after adaptation to distilled $\mathrm{H}_{2} \mathrm{O}$ and to $1.0 \mathrm{M}$ urea.

\section{Method}

Subjects. Fifteen Ss were used, 5 males and 10 females. None smoked and all were naive about the purpose of the study.

Solutions. The 12 test stimuli were the following: $0.0001 \mathrm{M} \mathrm{QHCl}$, $0.00001 \mathrm{M} Q H C 1,0.0001 \mathrm{M} \mathrm{QSO}_{4}$, $0.00001 \mathrm{M} \mathrm{QSO}_{4}, \quad 0.25 \mathrm{M} \mathrm{MgSO}_{4}$, $0.1 \mathrm{M}$ caffeine, $0.01 \mathrm{M}$ caffeine, $0.001 \mathrm{M}$ sucrose octa-acetate, $0.0001 \mathrm{M}$ sucrose octa-acetate, $0.0003 \mathrm{M} \mathrm{PTC}, 0.32 \mathrm{M} \mathrm{KNO}$, and $1.0 \mathrm{M}$ urea. The adapting stimuli were distilled $\mathrm{H}_{2} \mathrm{O}$ and $1.0 \mathrm{M}$ urea.

\section{Results}

Figure 3 shows the results of urea adaptation. Although adaptation to QHCl had no effect on the bitterness of urea in Experiments 1 and 2, adaptation to urea reduced significantly the bitterness of every compound affected by QHCl adaptation except caffeine and SOA. The effect of urea on these compounds was not as great as the effect of QHCl. While QHCl had a significant effect on the stronger concentrations of sucrose octa-acetate and caffeine, urea significantly reduced the bitterness of only the weaker of these stimuli. PTC was not affected by urea adaptation, and $\mathrm{KNO}_{3}$ was significantly reduced only in sourness. The two compounds which tasted both sour and bitter, $\mathrm{MgSO}_{4}$ and urea, were reduced significantly in both qualities by urea adaptation. It has been previously reported that urea adaptation induces a salty taste in distilled $\mathrm{H}_{2} \mathrm{O}$. (McBurney, 1969; Bogart, 1969). 


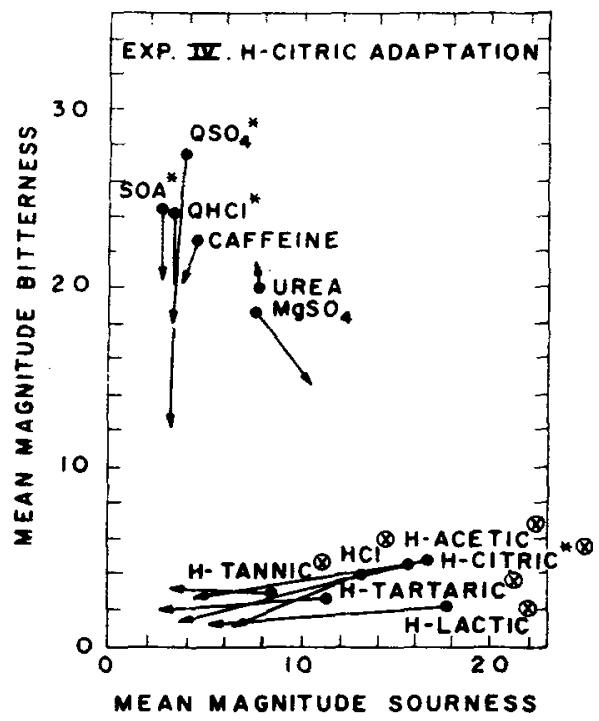

Fig. 4. Mean magnitude estimates of the sourness and bitterness of 12 stimuli after adaptation to distilled $\mathrm{H}_{2} \mathrm{O}$ and to $0.0004 \mathrm{M}$ citric acid.

Although not shown in the figure, urea adaptation caused a significant increase in the saltiness of several of the test stimuli (QHCl, QSO, caffeine, and PTC).

\section{EXPERIMENT 4:}

\section{CITRIC ACID ADAPTATION}

The results of the preceding experiments do not point to a simple situation for the coding of the bitter taste, as opposed to the straightforward mechanism implied by cross-adaptation experiments for the coding of saltiness (Smith \& McBurney, 1969). Citric acid was employed as an adapting stimulus in order to test its effects on the taste qualities of other acids as well as the bitter and sour-bitter stimuli that had been used in the preceding experiments on QHCl and urea adaptation.

Subjects. Fifteen Ss were used seven males and eight females. None smoked and all were naive about the purpose of the experiment.

Solutions. The 14 test stimuli were the following: $0.0064 \mathrm{M}$ lactic acid, $0.004 \mathrm{M}$ citric acid, $0.0064 \mathrm{M}$ acetic acid, $0.0032 \mathrm{M} \mathrm{HCl}, 0.001 \mathrm{M}$ tartaric acid, $0.0002 \mathrm{M}$ tannic acid, $1.0 \mathrm{M}$ urea, $0.25 \mathrm{M} \mathrm{MgSO}, 0.1 \mathrm{M}$ caffeine, $0.001 \mathrm{M}$ sucrose octa-acetate, $0.0001 \mathrm{M} Q H C l, 0.0001 \mathrm{M} \mathrm{QSO}_{4}$, $0.1 \mathrm{M} \mathrm{NaCl}$, and $0.18 \mathrm{M}$ sucrose. The adapting stimuli were $0.004 \mathrm{M}$ citric acid and distilled $\mathrm{H}_{2} \mathrm{O}$.

\section{Results}

The effect of citric acid adaptation on the sourness of other acids is presented in Fig. 4. Every acid tested was significantly reduced in sourness by citric acid adaptation. However, the sour tastes of $\mathrm{MgSO}_{4}$ and urea were not affected by citric acid adaptation. Both of these compounds were rated less sour and more bitter in this experiment than in Experiment 3 due perhaps to a contrast with the acids, making urea and $\mathrm{MgSO}_{4}$ seem more bitter than sour. When judged in the absence of the acids, in Experiment 3 , both urea and MgSO were considerably more sour than the other bitter compounds. It is also apparent from Fig. 4 that citric acid adaptation significantly reduced the bitterness of some of the stimuli (QHCl, $\mathbf{Q S O}_{4}$, and sucrose octa-acetate), even though citric acid was not itself appreciably bitter. This effect on the bitter stimuli is considerably less than that of QHCI adaptation. Sucrose and $\mathrm{NaCl}$, not shown in the figure, were not appreciably sour or bitter and were not affected in any way by citric acid adaptation. Both acetic acid and QHCl were significantly more sweet following citric acid adaptation. McBurney (1969) found that citric acid adaptation produced a sweet taste in distilled $\mathrm{H}_{2} \mathrm{O}$.

\section{EXPERIMENT 5: \\ QHCI, UREA, AND}

\section{CITRIC ACID ADAPTATION}

The cross-adaptation effects of the foregoing experiments were not always reciprocal between the various adapting-test solution pairs. Adaptation to QHCl had no effect on the bitterness of urea, while adaptation to urea significantly reduced the bitterness of QHCI. Each of the previous experiments involved a different group of Ss. The present experiment was designed to examine some adapting conditions not previously employed and to attempt to replicate on one group of Ss the effects studied in the first four experiments.

\section{Method}

Subjects. Twenty Ss were used, 8 males and 12 females. None smoked and all were naive about the purpose of the experiment.

Solutions. The 16 test stimuli were the following: $0.0064 \mathrm{M}$ lactic acid, $0.004 \mathrm{M}$ citric acid, $0.0064 \mathrm{M}$ acetic acid, $0.0032 \mathrm{M} \mathrm{HCl}, 0.003 \mathrm{M}$ tartaric acid, $0.002 \mathrm{M}$ tannic acid, $0.0001 \mathrm{M}$ QHC1, $0.00003 \mathrm{M} \mathrm{QSO}_{1}, 0.0001 \mathrm{M}$ sucrose octa-acetate, $0.1 \mathrm{M}$ caffeine, $0.25 \mathrm{M} \mathrm{MgSO}_{4}, 0.82 \mathrm{M}$ urea, $0.003 \mathrm{M}$ PTC, $1.0 \mathrm{M} \mathrm{KNO}_{3}, 0.1 \mathrm{M} \mathrm{NaCl}$, $0.18 \mathrm{M}$ sucrose. The adapting stimuli were distilled $\mathrm{H}_{2} \mathrm{O}, 0.0001 \mathrm{M} Q \mathrm{QCl}$, $0.82 \mathrm{M}$ urea, and $0.004 \mathrm{M}$ citric acid.

\section{Results}

The mean magnitude estimates of sourness and bitterness of all the test compounds except $\mathrm{NaCl}$ and sucrose are shown in Figs. 5-7. $\mathrm{NaCl}$ and sucrose were not reported as appreciably sour or bitter and were not significantly affected by adaptation to any of the adapting stimuli. The effects of QHCI adaptation on the test compounds may be seen in Fig. 5 . The results are essentially the same as in the previous QHCl adaptation experiments. The bitterness of $\mathrm{QHCl}, \mathrm{QSO}_{4}$, caffeine, and SOA is greatly reduced following QHCl adaptation. Urea was reduced significantly in bitterness in this experiment, although not as markedly as other compounds. None of the other compounds was significantly reduced in bitterness. The acids, which were not tested in the two previous $Q \mathrm{HCl}$ experiments, were not systematically affected by QHCI adaptation, although lactic acid was significantly less sour after QHCl adaptation.

Figure 6 shows the effects of urea adaptation. Both urea and $\mathrm{MgSO}_{4}$ were reported to be less sour when judged among a group of acids than in the previous experiments without the acids present. As before, both were significantly less sour and bitter following urea adaptation. Again, QSO, and SOA were significantly reduced in bitterness following urea adaptation. The effect on QHCl was not statistically significant in this experiment. The reduction in the bitterness of $\mathrm{QSO}_{4}, \mathrm{SOA}$, and $\mathrm{QHCl}$ was not nearly as great as that produced by QHCI adaptation. Urea adaptation had no systematic effect on the acids, although tartaric acid was

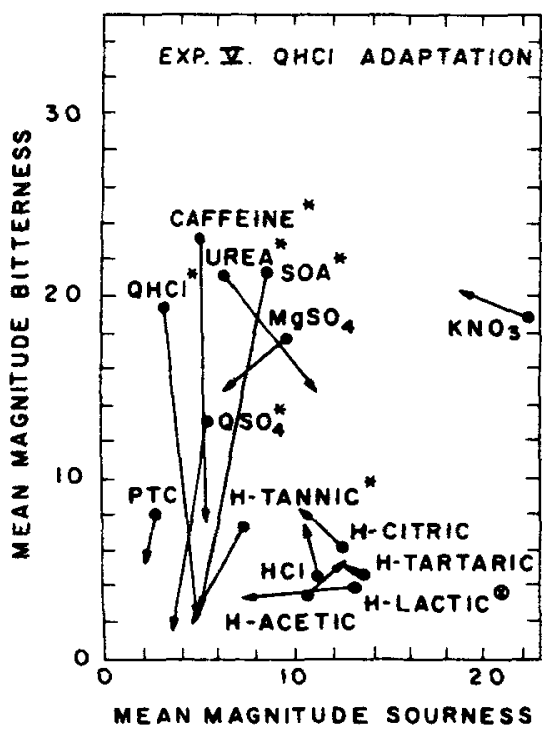

Fig. 5. Mean magnitude estimates of the sourness and bitterness of 14 stimuli after adaptation to distilled $\mathrm{H}_{2} \mathrm{O}$ and to $0.0001 \mathrm{M} Q \mathrm{HCl}$. 
reduced in sourness following adaptation to urea.

It may be seen from Fig. 7 that adaptation to citric acid produced the same results as in the previous experiment. All of the acids were significantly less sour following citric acid adaptation. Tannic acid and citric acid were also reduced in bitterness. $\mathrm{QHCl}$ and $\mathrm{QSO}$, were significantly less bitter following adaptation to citric acid, although this reduction was smaller than that after QHC adaptation. It appears from Fig. 7 that $\mathrm{KNO}$, increased in bitterness due to citric acid adaptation. This apparently large change was not a significant one and was the result of one very large response of one $S$ during one of the experimental conditions. The sourness of urea and $\mathrm{MgSO}_{4}$ was not affected by adaptation to citric acid.

\section{GENERAL DISCUSSION}

Although there are some differences in method and results between these various experiments it is important to note that each major effect was replicated at least once during a subeequent experiment. There are two fundamental trends apparent in the data. First, adaptation to citric acid reliably reduced the sourness of all other acids tested, implying that the sourness of acids may be coded by a single mechanism. That is the same conclusion reached earlier for the saltiness of inorganic salts (Smith \& McBurney, 1969). In contrast to this straightforward effect on the sourness of the acids, a more complex situation obtains with the bitter taste in these experiments. QHCl adaptation had a

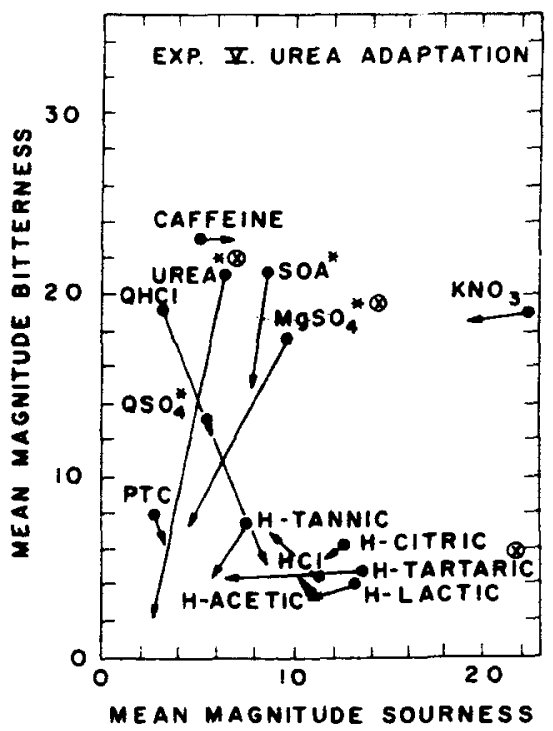

Fig. 6. Mean magnitude estimates of the sourness and bitterness of 14 stimuli after adaptation to distilled $\mathrm{H}_{2} \mathrm{O}$ and to $0.82 \mathrm{M}$ urea. pronounced effect on the bitterness of some of the compounds, but little or no effect on the bitterness of others, such as $\mathrm{MgSO}_{4}$ and urea (urea was significantly reduced in bitterness in one out of three experiments, although the effect was smail). Urea adaptation, on the other hand, had a significant effect on all of the compounds affected by QHCl adaptation, except for $0.1 \mathrm{M}$ caffeine, and for $\mathrm{QHCl}$ in Experiment 5. The magnitude of the effect of urea on these compounds, however, was less than that produced by adpatation to QHCl. The sourness and bitterness of $\mathrm{MgSO}_{4}$ and urea were quite markedly reduced by urea adaptation in both experiments. Two compounds (KNO, and PTC) that were reported as substantially sour and/or bitter were not affected by any of the adapting conditions ( $\mathrm{KNO}_{3}$ was significantly reduced in sourness by urea adaptation in one of two experiments). Citric acid also significantly reduced the bitterness of $\mathrm{QHCl}_{\text {and }} \mathrm{QSO}_{4}$ in both citric acid adaptation experiments. This effect, like that of urea on QHC, was of smaller magnitude than that of QHCl adaptation itself. However, neither QHCI nor urea adaptation had any systematic effect on either the bitterness or sourness of the acids.

These results appear at first glance to be somewhat unsystematic, but there are four main groups of compounds with some overlap between them. (1) Acids. These stimuli taste predominantly sour, are cross-adapted by citric acid, and are not systematically affected by adaptation to bitter compounds. (2) QHCl, QSO , SOA, and caffeine. These stimuli are all predominantly bitter and are markedly reduced in bitterness by adaptation to QHCI. Some of these compounds are affected to some extent by urea and citric acid adaptation, although some are not. None of them shown the pronounced reduction in bitternees to these other adapting stimuli that is produced by QHCl adaptation. (3) Urea and $\mathrm{MgSO}_{4}$. These compounds taste both sour and bitter. Adaptation to urea significantly reduces both taste qualities. Neither compound is affected by adaptation to QHCI or citric acid. (4) PTC and $\mathrm{KNO}_{3}$. PTC tastes predominantly bitter, while $\mathrm{KNO}_{3}$ appears to taste both sour and bitter. Neither compound is systematically affected by adaptation to QHCl, urea, or citric acid.

The main problem posed by the data appears to be that adaptation to urea and citric acid has a significant effect on the same compounds that strongly cross-adapt to QHCl. This effect could be the result of either partially common receptor processes

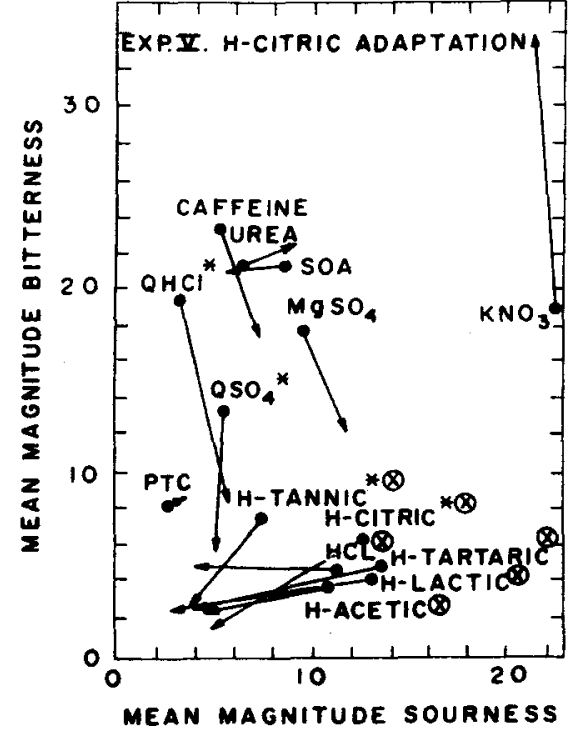

Fig. 7. Mean magnitude eximates of the sourness and bitterness of 14 stimuli after adaptation to distilled $\mathrm{H}_{2} \mathrm{O}$ and to $0.004 \mathrm{M}$ citric acid.

for these compounds or a verbal confusion between sourness and bitterness on the part of the Ss. Such a verbal confusion is well known (Bartoshuk, 1968; Meiselman \& Dzendolet, 1967; Robinson, 1970). An explanation in terms of verbal confusion requires the additional assumption that the degree of cross adaptation is dependent upon the degree of perceived similarity. This assumption is reasonable as long as the perceived similarity depends strictly upon the similarity of the coding mechanisms between two stimuli. However, if the similarity due to verbal confusion were to contribute to cross adaptation, it would seriously reduce the power of the cross-adaptation experiment as a test of receptor commonality. As a teat of the verbal confusion hypothexis, we correlated, across S3, the ratings of the bitterness of urea with the marnitude of the reduction of the bitternes of QHCI by urea adaptation. That is, would those $8 \mathrm{~s}$ wo judged urea to be more bitter (more like QHCI) show more crose adaptation than S, who found urea to be sour? There was no appreciable correlation. Similarly, there was no appreciable correlation across $S 3$ between the perceived bitterness of citric acid and the reduction of the bitterness of QHCl following citric acid adaptation. Thus, the effect of urea and citric acid adaptation on the bitterneas of QHCl does not appear to be the result of a simple confusion between sourness and bitterness.

It seems likely, then, that the nonreciprocal effects between QHCI 
and urea or citric acid are due to partial commonality of their receptor processes. If we conceive of adaptation as occurring by the filling of receptor site (Beidler, 1953, 1962), then there may be two or more sites responsive to urea and citric acid and one for $\mathrm{QHCl}$. The $\mathrm{QHCl}$ site accepts urea and citric acid. Thus adaptation to either citric acid or urea will cause a reduction in the response to $\mathrm{QHCl}$, depending on the number of such sites and the relative affinities of these compounds for them. The fact that urea affects $\mathrm{QHCl}$ and $\mathrm{QHCl}$ affects caffeine but urea does not affect caffeine remains a problem in this model. The effect of urea on the weaker caffeine indicates that there is some commonality between the receptor mechanisms involved in urea and caffeine. It is possible that an explanation might be developed in terms of relative affinity and competition between these compounds for a site.

In summary, the data from this series of experiments suggest that there may be single mechanisms for coding the salty, sour, and sweet tastes but that the bitter taste does not seem to be coded by a single receptor mechanism. The data do not allow for any firm conclusion as to whether there are more than two mechanisms for the bitter taste.

\section{REFERENCES}

BARTOSHUK, L, II, Water taste in man. Perception \& Psychophysics. 1968, 3. 69-72.

BEIDLER, L. M. Properties of chemoreceptors of tongue of rat. Joumal of Neurophysiology, 1953, 16, 595-607.

BEIDLER, L. M. Taste receptor stimulation. Progress in Biophysics \& Biophysical Chemistry, 1962,12,107-151.

BOGART, L. M. A salty taste following urea adaptation: Implications for a mechanism encoding saltiness. (Doctoral dissertation. University of Pittsburgh) Ann Arbor, Mich: University Microfilms. 1969,
No. $70-5371$.

HAHN, H. Beitrage zur Reizphysiologie Heidelberg: Scherer, 1949

MCBURNEY, D. H. Magnitude estimation of the taste of sodium chloride after adaptation to sodium chloride. Journal of Experimental Physiology, 1966, 72 , 869-873.

McBURNEY, D. H. Effects of adaptation on human taste function. In C. Pfaffmann (Ed.). Olfaction and taste III. New York: Rocke feller University Press, 1969.

M cBURNEY, D. H. Gustatory cross adaptation between sweet tasting compounds. Perception \& Psychophysics. 1972. 11, 225-227.

MEISELMAN, H. L.. \& DZENDOLET. E. $V$ ariability in quality identification Perception \& Psychophysics, 1967. 2. $496 \cdot 498$.

ROBINSON. $j$. 0 . The misuse of taste names by untrained observers. British Journal of Psychology, 1970, 61, 375-378.

SMITH, D. V. \& MCBURNEY, D. H Gustatory cross-adaptation: Does a sinple mechanism code the salty taste? Journal of Experimental Psychology, 1969,80. 101-1C5.

(Received for publication July 6, 1971.) 